\title{
Thinking on the Correlation Between Bauhaus and Computational Design Education
}

\author{
* Ph.D. Candidate Selin Oktan ${ }^{1}$ (D) and Dr. Serbulent Vural ${ }^{2}$
}

Department of Architecture, Faculty of Architecture, Karadeniz Technical University, 61080, Trabzon, Turkey 'Email: selinoktan@ktu.edu.tr ,2Email: svural@ktu.edu.tr

\begin{tabular}{|l|}
\hline A R T I C L E I N F O: \\
\hline Article history: \\
Received 30 December 2018 \\
Accepted 1 June 2019 \\
Available online 20 June 2019 \\
\hline Keywords: \\
Bauhaus; \\
Computational \\
Thinking; \\
Computational \\
Design Education; \\
Digital Design; \\
Digital Revolution. \\
\hline
\end{tabular}

This work is licensed under a Creative Commons Attribution NonCommercial - NoDerivs 4.0. "CC-BY-NC-ND"

\begin{abstract}
A B S T R A C T
This study assesses that there are similarities between Bauhaus movement and computational design. The similarities are discussed under the titles of hands-on activities, interdisciplinary studies and relation with technology for both Bauhaus and computational design. Digital technology is changing rapidly, and to catch the developing technology up the education system must be updated. Bauhaus can be a pathfinder for computational design education. Within this context, three educational organizations, KTU CODE FAB, IAAC and ICD, which were experienced personally, are examined. As a result of the study, it is reduced that; the innovative spirit of Bauhaus, which focuses on doing and hands-on activities, is also important for the computational design education. The well-trained architects that accustomed to the new technology can be graduated with the integration with industry, similarly to the Bauhaus system.
\end{abstract}

JOURNAL OF CONTEMPORARY URBAN AFFAIRS (2019), 3(3), 27-38.

https://doi.org/10.25034/ijcua.2019.v3n3-3

WWw.ijcua.com

Copyright (C) 2019 Journal of Contemporary Urban Affairs. All rights reserved.

\section{Introduction}

Bauhaus School was established in the technological revolution period that happened at the beginning of twentieth century. The technological revolution of Bauhaus' time came up with new construction techniques, technology and materials. Bauhaus aimed to integrate the new technology with the architecture and to build a new kind of architectural education that emphasizes on crafts. Gropius (1919) asserted that teaching craft was one of the most important achievements of Bauhaus. Because it sought answers to how a designer should be trained to become a master in the machine age (Bayer, Gropius, \& Gropius, 1938). A similar question can be asked today, "How a designer could adapt to digital revolution?".

There is a similarity between Bauhaus' Industrial Revolution and today's digital revolution period, in terms of technological developments and its effects to architecture. The Modernism style has emerged as a result of

*Corresponding Author:
Department of Architecture, Faculty of Architecture,
Karadeniz Technical University, 61080, Trabzon, Turkey
E-mail address: selinoktan@ktu.edu.tr


the Industrial Revolution. As a result of the revolution, some new concepts such as mass production, purity, simplicity, standardization, etc. began to be discussed as a part of design process. Especially mass production led to standard sized materials and modularization in design. It was emphasized that these kinds of new approaches could not be integrated with the existing design environment and a new architecture that represents the spirit of that era had to be created (Bayer et al., 1938). Similarly, today we are witnessing a transformation in architecture which is a result of digital revolution, in terms of design and fabrication processes. Modernist discourses are insufficient to discuss today's digital design processes and products. Because as is in Industrial Revolution period, the new approaches cannot be adopted to today's existing architectural environment, either. Today, the fabrication techniques and design processes are turning into human and machine collaboration. A different kind of design process is developing, and therefore, updates are needed to understand and discuss it.

Bauhaus was the pioneer of its day, because it aimed to understand the new technology with hands-on activities. Also, it brought a new type of architectural education system that integrates the industry with art and design. It removed the borders between arts and crafts (Hochman \& Ashton, 1997). Today, digital design and fabrication processes are trying to be integrated with the industry, too. This leads to the assertion that; Bauhaus might be a pathfinder for the question aforementioned: "How a designer could adapt to the digital revolution?".

The similarities between Bauhaus' Industrial Revolution period and today's digital revolution period is the starting point of this study. From this point of view, the main aim of this study is to discuss how the architectural education system should be transformed to catch the new technology up. The assertion of this study is that; Bauhaus education system can be a guide for teaching computational design which is related with the digital revolution. To discuss this assertion Bauhaus education system is analysed in three titles; hands-on activities, interdisciplinary studies and relation with industrial technology. First of all, these three titles' meanings for Bauhaus education system are discussed. Then the same titles are discussed for computational design processes. In that part of the study three educational organizations, which were experienced personally, are examined. The first one is KTU CODE FAB, which is a computational design and fabrication laboratory established as a part of Karadeniz Technical University Department of Architecture located in Trabzon / Turkey, the second one is IAAC, which is an institute of advanced architecture located in Barcelona / Spain and the last one is ICD, which is an institute for computational design located in Stuttgart / Germany. At the end of the study, the similarities and differences are reviewed, and the future of computational design education and Bauhaus' role on it is discussed.

\section{The Structure of Bauhaus Education System}

Bauhaus education system is based on handson activities, making the new industrial technology a part of architecture and integration of arts and crafts. Within the context of these concepts a three-staged education system was built (Figure 1). This education process begins with a basic design course which is originally called "Vorkurs" and lasts for six months. This basic course was one of the most important achievements of Bauhaus, pedagogically. This course was based on form, colour and material instruction, and the course's intructors were the art teachers at the Bauhaus (Siebenbrodt \& Schöbe, 2009). The second stage of the education process was the workshops concentrated on various materials. This stage was the core of the Bauhaus education system, and the hands-on activities were carried out in that three-years period. The last stage was about gaining experience in the field of building methods. In this stage hands-on activities were applied on site with 1:1 scaled building.

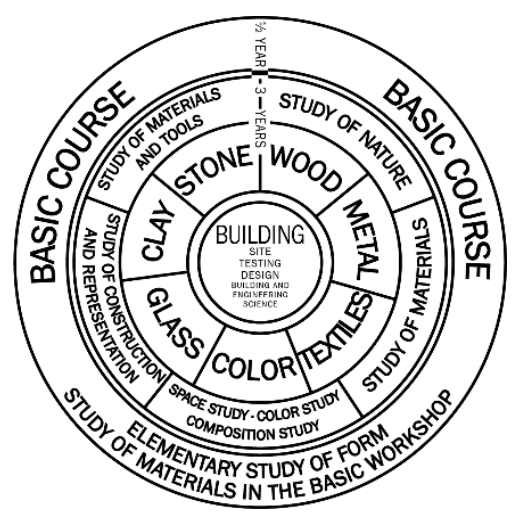

Figure 1. Bauhaus education circle (Makered, n.d.).

Hochman and Ashton (1997) claims that Bauhaus effected today's modern art 
education in two ways. The first one is "Vorkurs", which is an introductory course that helps the students explore their talents. The second one is integrating the workshop studies with various disciplines such as art (Hochman et al., 1997). In addition to these effects, the other common point between Bauhaus and today's computational design are hands-on activities and gaining experience with 1:1 scaled construction.

\subsection{Hands-on Activities in Bauhaus Education System}

The hands-on activities are insufficient in conventional education system and to make the students personalize the learning process, learning by doing activities must be increased (Dewey, 1938). One of the most important outputs of the Bauhaus education process is that; every student had to learn at least one craft (Bayer et al., 1938). In Bauhaus education system, hands-on activities are at the core of the education process and these activities are supported with workshop studies such as; clay, stone, wood, metal, textile, glass, colour ateliers. These hands-on activities differ from today's conventional education process' doing techniques. Today, in conventional architectural education process, physical model making is only used as a visualisation technique. Despite that, doing at Bauhaus is for understanding the design, questioning and seeing the problems and developing a construction method.

Gropius was an advocator for the thought that architecture was best be learned through hands-on practice, and he supported a learning process that was arranged by students themselves, and without too many rules (Hochman et al., 1997).

The Industrial Revolution transformed the construction styles dramatically. In order to catch the developing technology up, integrating hands-on activities and learning by doing are essential. From this point of view, the workshop studies, which form the basis of Bauhaus, gave a chance to investigate and develop mass-production and the technology, as if a laboratory (Gropius, 1965). To experience arts and crafts together and learning by doing in the education process make the students question the design process, confront the design problems and be a part of a team.

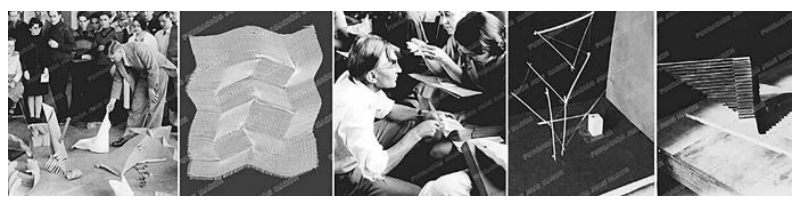

Figure 2. Hands-on activities in the Bauhaus system (Albers, 2014).

The frame of Bauhaus is an example for constructivist approach in today's education literature. The constructivist approaches require learning process to be integrated with the experiential activities (Jonassen, 1992). In this way the students could internalize the knowledge. The teaching approaches evaluated from objectivist to constructivist approaches (Jonassen, 1992). Objectivist approach means teaching the knowledge in a direct way with the definitions. In that learning style the student plays a passive role. But constructivist approach teaches it with the real-world problems, and the student plays an active role. The process gets more constructivist when hands-on activities become a part of it.

Gropius (1919) in the Bauhaus Manifesto emphasized that; an education system without class divisions had to be created. This refers a master - apprentice relation, more than a professor - student relation. This approach is also valid for some of the computational design education systems. It can be said that; Bauhaus did not only effect architectural education with the teaching styles but also with the way of thinking and social approaches.

\subsection{Interdisciplinary Studies in Bauhaus Education System}

One of the Bauhaus' aims is to bring the designers, artists, technicians and industry together. Bauhaus workshop studies were carried out by the instructors from various disciplines, such as painters, sculptors, etc. Painter and art theorist Wassily Kandinsky organized workshop on colour, artist Joseph Albers on material, painter Paul Klee on balance of form, sculptor Oscar Schlemmer on drawing and sketch, and George Munch on weaving (Salama, 1995). Bauhaus students were responsible for learning at least one craft method properly, and the interdisciplinary studies at Bauhaus provide knowledge about crafts for the students. The learning process associated with crafts is significant for catching the industrial technology up. Because these kinds of studies gave chance to experience 
the technology by using both conventional and new materials of that time.

The interdisciplinary studies at Bauhaus mostly carried out with artists. One of the most wellknown notions of Bauhaus "The art is an exalted craftsman." (Hochman et al., 1997) shows that; the art is also a way to learn crafts and mechanical technology. Performing workshops with various disciplines enable students to develop a new point of view for design and to learn various fabrication methods that is useful for the mechanic technology knowledge. Because of these reasons, the workshop studies that related with art, formed the beginning of the educational curriculum.

\subsection{Relation with Industrial Technology in Bauhaus Education System}

Bauhaus workshops, as if a laboratory, had the opportunity to develop the technology of its age (Gropius, 1965). Because experiencing the machine gives the knowledge of its working principle. This provides an opportunity for developing the technology. At Bauhaus, machine was seen as an improved hand tool. It was asserted that it was not possible to understand an industrial machine without understanding a simple hand tool (Peter, 1994). Pye (1978) asserts that the invention comes before the theory. That means making comes first, and then we start to think about it. These making and thinking processes lead to new inventions or developments. Within this context it can be said that; contrary to popular belief, science follows technology (Cross, 1982).

Industrial technology is at the core of the Bauhaus and it was successful in teaching the students new technology. The graduates form Bauhaus school were one of the most soughtafter employees for the industry (Gropius, 1965). At Bauhaus, industrial technology and hands-on activities feed each other. It is believed that the proficiency of an artist in the field of craft is related to his knowledge about industrial fabrication.

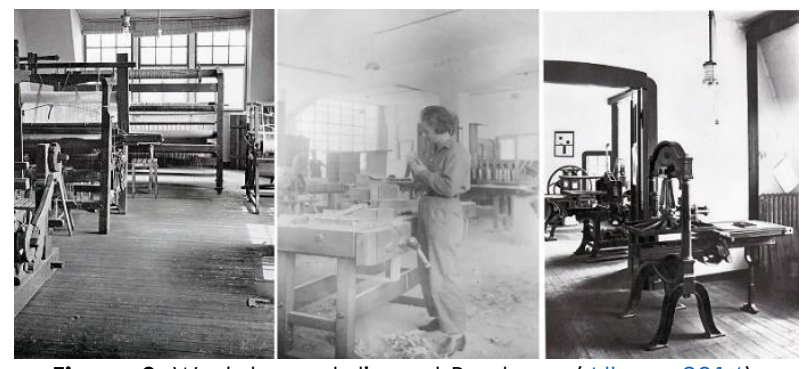

Figure 3. Workshop ateliers at Bauhaus (Albers, 2014).
The effects of Bauhaus education still can be seen in today's architectural education system. Bauhaus system has a potential to lead to technology-oriented education systems. Relation with technology and learning by doing complement each other. Teaching the technology without practicing would fail. The three focal points of Bauhaus, learning by making, interdisciplinary studies and integrating with industrial technology, is also significant to teach digital technology in today's architectural education.

\subsection{Thinking Bauhaus as a Pathfinder within the Context of Computational Design Education}

The production technology was changed dramatically by the mass-production system, after the Industrial Revolution and Bauhaus succeeded to integrate that new technology with the architectural education. Today, we are witnessing a similar transformation with the developing digital technologies. To be integrated and to catch up with this new technology in the field architecture, architectural education system should be updated. Within this context, Bauhaus workshops' constructivist education approach can be a guide for developing today's computational design education system.

In computational design age, the designers have a new problem that; expressing the design process to the machine. Because the human - machine collaboration is a key point for both design and fabrication processes. This collaboration makes the design process more implicit and lead to think on and to design the design process. Even though Modernism doctrine is still important for conventional architectural education; today, a technological reform is happening, and Modernism discourses fail to satisfy to discuss the new design and fabrication methods brought by digital revolution. Therefore, new discourses are needed in order to evaluate the computational design process in both theoretical and educational field.

As aforementioned before, the schools where computational design education is a part of education system are researched, and it is seen that the computational design process is integrated with hands-on activities, interdisciplinary studies and digital /industrial technology, which is the same as Bauhaus. To discuss these titles within the context of computational design education, some 
educational processes of KTU CODE FAB, IAAC and ICD are discussed.

\subsection{Hands-on Activities in Computational Design Education}

Learning by doing at Bauhaus was discussed as a part of integration with material and construction methods. For example; the stone in the sculpture atelier, the wood in the carpenter atelier, the textile material characteristics could be learnt in weaving atelier. This atelier experience is important because it leads to discuss the relation between material knowledge and fabrication methods. When the computational education processes for selected examples are researched, it is deduced that hands-on activities in computational design processes are carried out in various ways. These can be categorized as:

- Focusing on 1:1 scaled production,

- Integrating material technology with the digital fabrication,

- Developing the digital fabrication technologies,

- Focusing on computational thinking, and all these categories are related with doing / hands-on activities.

The main point for experimenting the digital fabrication tools in architecture is to figure out how we could adopt these techniques to architectural construction. To gain this ability, small scaled 1:1 structures are designed and fabricated. Thus, it becomes possible to see the problems about digital fabrication processes and improving the digital fabrication techniques.

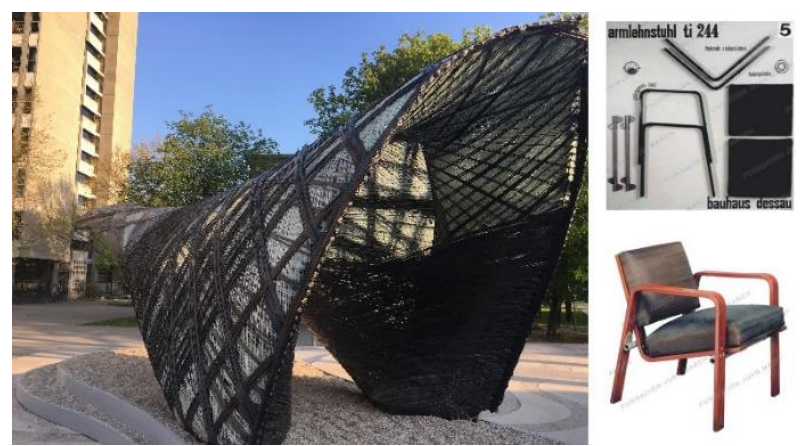

Figure 4. 1:1 scaled structure designed by ICD in 2017 (Photo by the author) and $1: 1$ scaled furniture design at Bauhaus (Albers, 2014).

Computational design process encourages the designers to go beyond the standard Euclidean forms and to design complex or curvilinear shapes, because it makes that kind of forms drawable and applicable in a simpler way than conventional design process. The more complex or curvilinear shapes bring the new material behaviour studies. The new material technology such as carbon fibre (Figure 4) or traditional materials such as clay (Figure 5) can be a part of this material studies. At Bauhaus the material studies focused on the new material technology such as glass, metal; or to use the traditional materials such as clay, stone in a modernist manner. In computational design processes it is only important to bring the existing material technology and digital fabrication processes together.

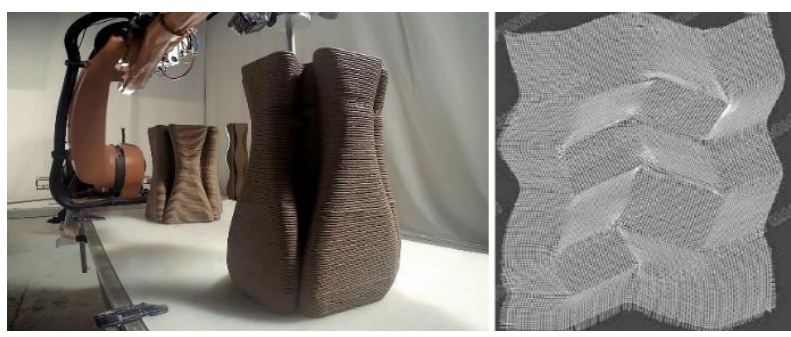

Figure 5. A robotic 3D print fabrication at IAAC (IAAC, n.d.) and a material study at Bauhaus (Albers, 2014).

Integrating the digital fabrication technology with various materials, brings new perspectives to the technology. These kind of fabrication processes also related with developing the new technology. Because existing conventional fabrication methods may be insufficient to response computational design products. To build computationally designed structures, machines must become involved in the process, but sometimes two or more fabrication tools must work together. Therefore, various technologies should be brought together. For example; a clay study carried out at IAAC brings $3 \mathrm{D}$ printing and robotic technologies together (Figure 5). This causes to develop a new fabrication technique that could be called as robotic 3D printing.

All those human - machine or machine machine collaborations require to think in a computational way. Computational thinking means to describe the design or fabrication process step by step as if an algorithm. Describing the process to a machine is not something we used to do. An exercise that carried out at KTU CODE FAB tried to teach the students how a machine works (Figure 6). 

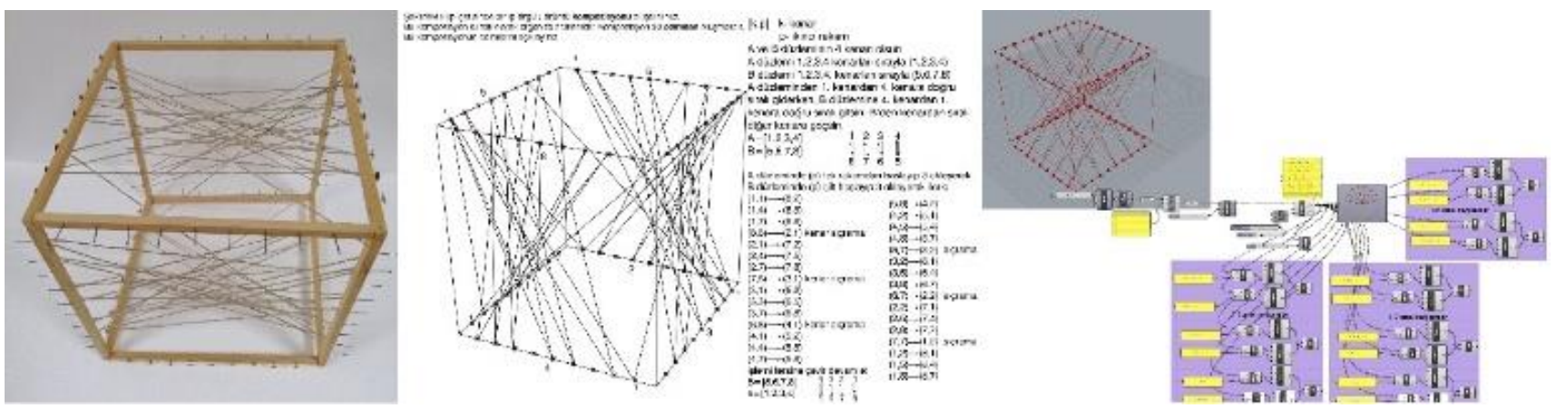

Figure 6. A computational thinking process carried out at KTU CODE FAB

The exercise begins with a conventional doing process. Every group create a knitting pattern on the edges of a cube. Then the students try to explain the production process step by step. With this, g-code's operating logic is tried to be understood. In the second image of Figure 6 shows the process step by step that looks like a g-code. While the students try to explain the process, they see that explaining something to a machine or thinking like a machine brings a different way of thinking.

To teach the computational thinking at KTU CODE FAB, some elective courses are carried out at undergraduate level, and two different methods aimed at the integration of computational thinking with doing have tried. The first one of these methods is that the exercise process starts in digital environment and ends with hands-on activities; the second one starts with hands-on activity and ends with applying the similar process in digital environment by using the software Grasshopper, which enables an algorithmbased modelling.

In the first method a design task is given to the students. In the course process, the biggest challenge for the student is that; learning a new software as well as trying to solve a design problem. At the end of the study, when the final products were evaluated it was seen that parameters could not be defined properly. A properly defined algorithmic model must provide an opportunity for various design alternatives when the parameters are changed. But for example, in Figure 7, two different design alternatives for one design problem are seen and while the first one is expressive for the design problem, but the second one with different parameters is not a meaningful design. Trying various alternatives on the same 3D model is one of the most important advantages of computational design. And for this study it could not be managed properly by the student. This means that, the way of computational thinking was not understood enough.

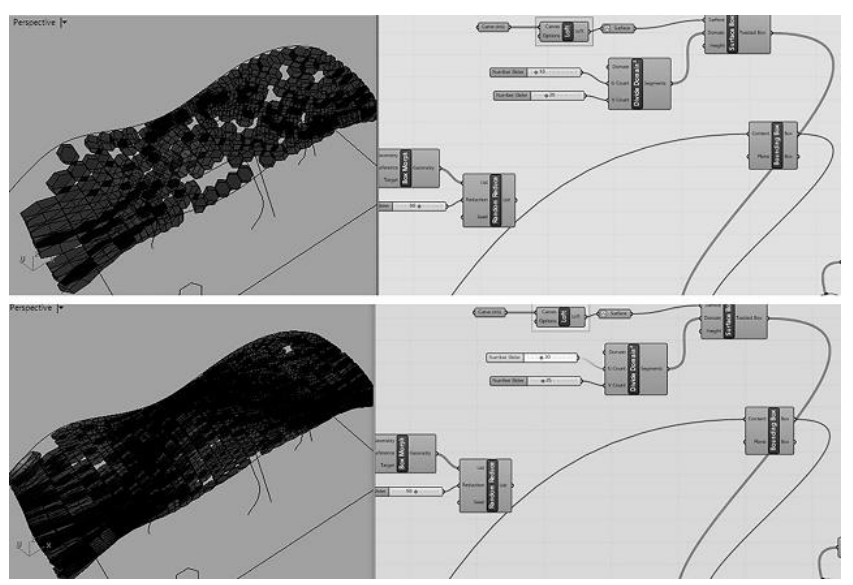

Figure 7. The Grasshopper models with various parameters.

Computational thinking, as if developing an algorithm, requires describing the process step by step and thinking it as a system of parameters and actions. Because the main aim of computational design is creating a "space of solutions/designs" on the same 3D model. Thus, various design alternatives can be tried in a short time. In Figure 8 the differences between first and second Grasshopper models of a student is seen. In the first Grasshopper model the parameters of "Polygon 1" and "Polygon 2" are defined as unrelated parameters despite they are related. Under this circumstance, when the " $h$ " parameter of Polygon 1 changed, the "b" parameter of Polygon 2 stays the same, because they are not connected to each other. Thus, the 3D model is not updated according to new parameters. In the second model, the parameters are related with each other such as $r-r \times 2, h-h / 6$. Thus, the 3D model is updated for every new parameter and a design space can be created properly. 


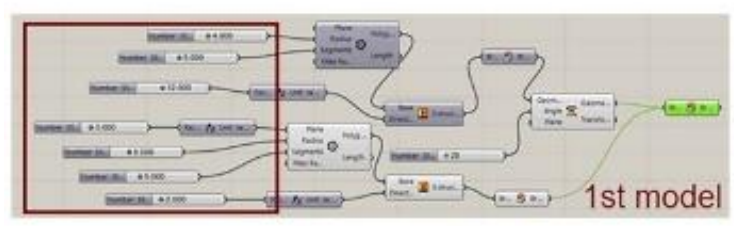

1st Grasshopper Model:

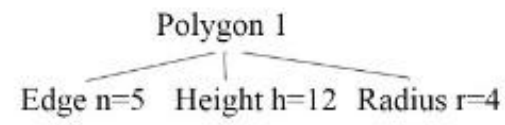

$\underbrace{\text { Polygon } 2}_{\text {Edge } \mathrm{a}=5 \text { Height } \mathrm{b}=2 \quad \text { Radius } \mathrm{c}=8}$

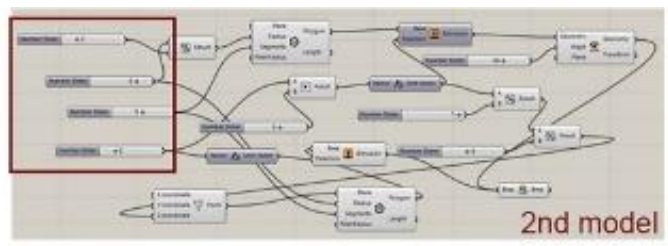

2nd Grasshopper Model:

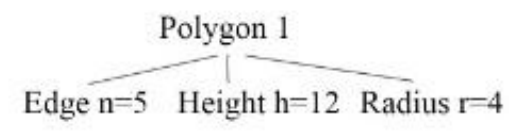

Polygon 2

Edge $=\mathrm{n}$ Height $=\mathrm{h} / 6$ Radius $=\mathrm{r} \times 2$

Figure 8. Differences between first and second Grasshopper models of a student.

In the second method, unlike the first one, a hands-on activity was carried out first and a physical model was produced. As is seen in Figure 9, the construction phase of physical model was written down step by step to see how an algorithm works. The steps led to the Grasshopper model, and it was seen that; Grasshopper algorithms were defined more easily than the first method, because the design was created at the beginning of the design process, so the students concentrate on the Grasshopper model rather than the design. Also, the design steps' and so Grasshopper algorithms' framework was clear.

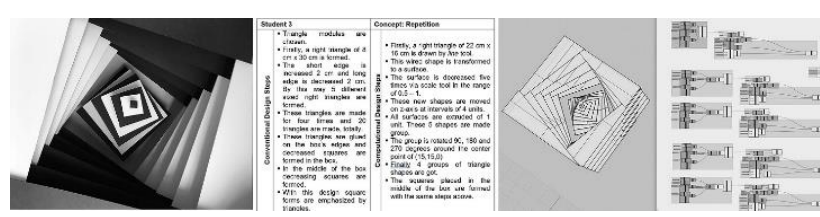

Figure 9. An example of the second method: the physical model, the design steps and the 3D model.

Computational thinking makes design process to be described more explicitly. Because of the parameters and the design phases are observable, the process can be tracked. In computational design processes the design process is designed as well as the final product. The conventional architectural education process, which is under the influence of modernist doctrine, students have some problems to carry out that kind of explicit design process. Supporting the design process with hands-on activities makes the computational design process more understandable.

\subsection{Interdisciplinary Studies in Computational Design Education}

Bauhaus integrated various disciplines such as designers, artists to work together, and this method succeeded to train sophisticated architects. The interdisciplinary studies help designers to see in a different perspective. The field of communication developed considerably as a result of digital technology; thus, more than one people be able to work on the same task easily, owing to the tools such as cloud system. People do not even have to be in the same place to work together, and this supports the collaboration of various disciplines. In addition to Bauhaus' designer artist - industry cooperation, science and architecture collaboration is also important for computational design processes. When the groups who work on experimental studies about computational design are scrutinized; we see that various disciplines such as designers, biologists, mathematicians, software developers, engineers, etc. work together. Thus, the design process can be accomplished in a multi-directional approach, and more detailed studies can be carried out on the innovations of digital era.

The interdisciplinary studies in computational design makes architecture closer to science. Biomimicry as a design approach could be an example to explain this situation. One of the ICD's Research Pavilion that was built in 2013 2014 is based on biomimicry. In this design process, various disciplines such as designers, 
biologists, software developers worked together, and the design process was managed as a scientific process.

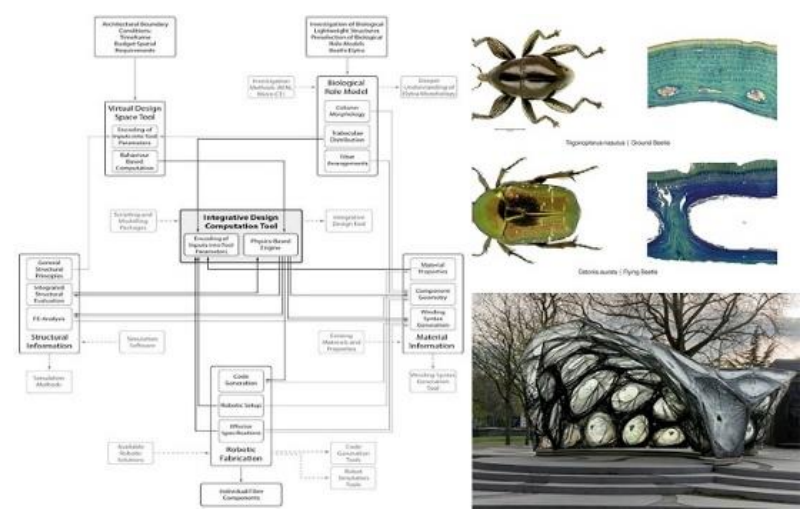

Figure 10. An example of biomimetic design, (ICD, n.d.).

The disciplines of biology and architecture have always been in a close relation for years. The relation between them sometimes be reflected as analogy, and sometimes as biomimicry. With the development of computational design studies another relation has been added to architecture - biology cooperation; the generative designs. Generative designs are a result of the process of generative algorithms, which is based on evolution of the species. In a generative design process, design alternatives are created by the computer, and the designer's role here is to define the parameters and algorithms about design problem. In that process the designer behaves as a software developer, but the designer still effects the final design directly. In that approach, the designing process is designed.

The interdisciplinary approaches in computational design brings new course contents to the architectural education. The students need to learn to use the computer not only as a presentation tool, but also as a design assistant. A need of learning a coding language in architecture emerges. This makes interdisciplinary studies in the architectural education a necessity. The hands-on activities in architecture also brings an interdisciplinary study. For example, to make a wooden structure in 1:1 scale the designer must be in related with the disciplines of metallurgy, structural engineering, forest engineer, etc. With these interdisciplinary relations in architectural education, more sophisticated architects can be trained.

\subsection{Relation with Digital Technology in Computational Design Education}

At Bauhaus, the prototypes of designs were mostly built by hand, and this process was carried out as if a fabrication method (Gropius, 1965). During the Bauhaus workshop process imitating the production techniques of a machine by hand aimed to understand the working principle of the machine. Today, the machines of Bauhaus era have been digitalized and different kinds of machines have been introduced. Some new categories of fabrication tools and methods have showed up as a result of digitalization. These methods are categorized as additive, subtractive, formative fabrication processes (Kolarevic, 2003). 3D printers are the examples of additive, CNC laser cutting machines or milling machines are subtractive, robotic manipulators are formative, additive and subtractive.

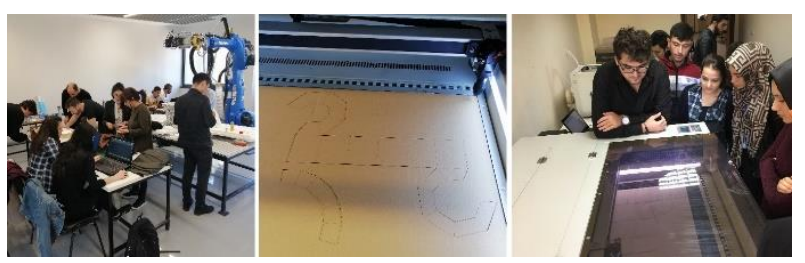

Figure 11. Working with digital fabrication tools at KTU CODE FAB (Photos by the author)

As a result of Industrial Revolution massproduction has become a standard production style. In today's fabrication processes the standard mass-production process is transforming into a non-standard mass-production. The institutes like IAAC, which bases its educational curriculum directly on digital fabrication, puts the industrial machines and fabrication methods at the core of its education process (Figure 12). IAAC is also an important example for being a part of Fab Lab Organization with the "Fab Lab Barcelona".

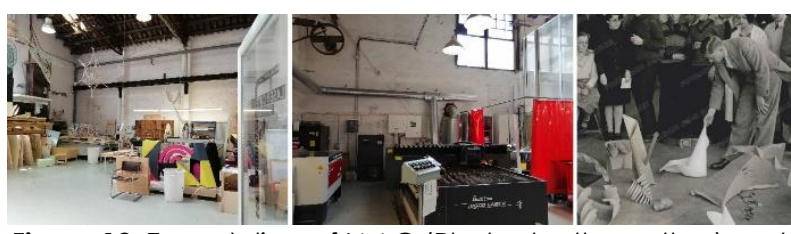

Figure 12. Two ateliers of IAAC (Photos by the author) and a workshop at Bauhaus (Albers, 2014).

Fab Lab Organization was established as a result of a study at Massachusetts Institute of Technology's Bits and Atoms Centre. And it has spread all over the world (FabLabs, n.d.). Fab 
Labs are a network that share their machines and data about digital fabrication with each other to deepen the knowledge. These organisations make the relation between industry and design disciplines visible. Fab Labs contribute to both education and digital fabrication processes, and from that point of view they can be likened to Bauhaus movement.

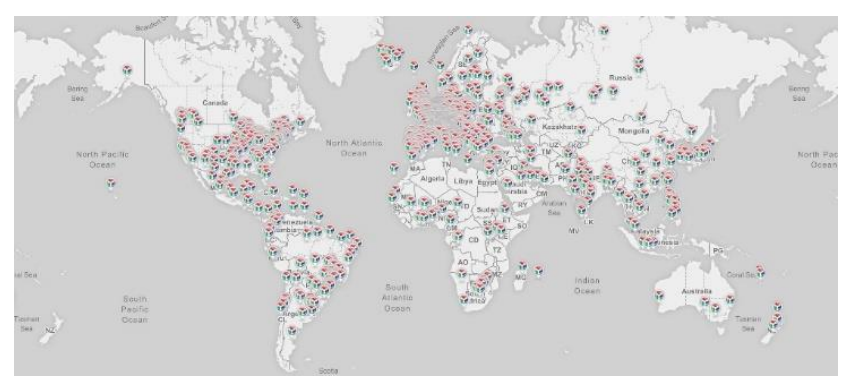

Figure 13. The map of Fab Labs over the world (FabLabs, n.d.).

Within the context of the discussions in the study, it can be understood that, Bauhaus era and today have some common points. This year, 2019, we are celebrating Bauhaus' 100th year anniversary. Due to this celebration a small scaled pavilion called "Tiny Bauhaus" is built in front of the Mies van der Rohe's Barcelona Pavilion, which is a representative work for Modernism. The Tiny Bauhaus Pavilion is remarkable because of its fabrication techniques. It is fabricated with a robotic 3D printing method. This reference shows that the Bauhaus spirit and its relationship with its time's technology still inspires designers about being in a relation with today's digital technology. This is an evidence for the similarity between Bauhaus and computational design process.

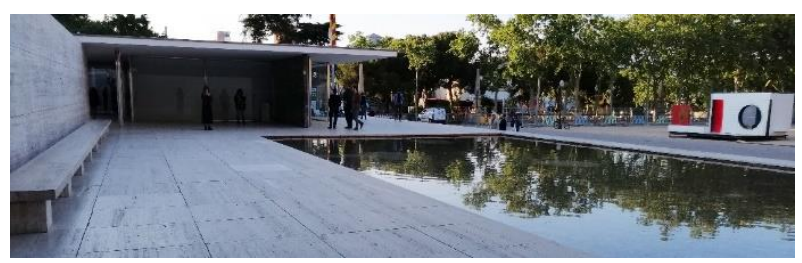

Figure 14. Tiny Bauhuas Pavilion, Barcelona / Spain (Photo by the author).

\section{Discussions and Results}

Within the context of this study the similarities between the spirit Bauhaus and computational design are discussed. Bauhaus' effects on architectural design and architectural education process are still perceived. It is emphasized that; Bauhaus has a potential for being a pathfinder for updating the architectural education to meet the requirements of digital design age. The relationship between Bauhaus movement and computational design thought is summarized as:

- Bauhaus movement emerged as a result of Industrial Revolution; computational design thought is under the influence of digital revolution.

- Bauhaus aimed to bring arts and crafts together, and it succeeded; in computational design processes various disciplines such as designers, engineers, mathematicians, software developers work together.

- In the Bauhaus era the massproduction methods were in demand; computational design processes focus to improve non-standard massproduction methods.

- The mechanic technology was a tool of the designer in Bauhaus, the digital technology is a tool in computational design.

- Both Bauhaus and computational design education processes focus on hands-on activities.

- Both internalise constructivist approaches in education.

- Both bring a new architectural approach / thought.

- At Bauhaus the relation between professor and student relation depended on master - apprentice relation; in computational design education this relation evolves into the relation that instructor and student work and experience together.

Technology is developing at a great pace and it leads to a competition between countries. As in all fields of science and fabrication, integration with technology in the field of architecture is one of the important of research topics of today. Especially in Europe and United States of America, various studies have been carrying out to integrate the computational thinking and digital fabrication with architecture. Universities are dominating this field by the studies that focus on fabrication and education. In addition to these developments, in some schools, computeraided design with conventional methods are still frequently used methods, and there are still controversies about the role and necessity of designing and fabricating computationally. The reason is that, the thought of a design 
process must be related with emotions and if a computer is involved in a design process, the design would become a meaningless thing. But contrary to this belief, computers' and digital fabrication tools' becoming a part of the design process does not make the design meaningless or does not ignore the designer's emotions and talent. The computer helps the designer to produce more ideas in less time.

The innovative spirit of Bauhaus, which focuses on doing and experiencing, is a guide for the reflection of digital revolution on the computational design education. The aforementioned three basic features of Bauhaus can be considered as the outline of digital design education.

When we ask again the question of this study, "How a designer could adapt to digital revolution?"; we see that these must be provided within the education system:

- Integrate the education process with the digital fabrication tools,

- Introduce the digital technology to the undergraduate level,

- Bring the courses that focuses on digital fabrication to compulsory course status,

- Supply an experimental environment to the students,

- Teach the student how to think computationally,

- Teach to students how to work with different disciplines.

The ability of thinking computationally is the base of computational design process. The skill of thinking computationally could be increased independently of computer or digital environment. From this point of view, to integrate the digital technology with architecture, the courses that aims to increase computational thinking skill can be carried out with first graders. This skill can be integrated with digital technology as the student gets through the education process. For this purpose, it is important that computational design contents should be instructed not only as elective but also as compulsory courses. This process could be supported with fabrication methods and laboratory experiments. Hereby, the well-trained architects that accustomed to the new technology can be graduated, similarly to the Bauhaus system.

\section{Acknowledgements}

This study was supported by Karadeniz Technical University Unit of Scientific Research Projects (KTU BAP). (Project ID: 7252 - Project Code: FAY-20187252)

\section{Conflict of interests}

The authors declare no conflict of interest.

\section{References}

Albers, J. (2014). Josef Albers: Minimal means, maximum effect. Madrid: Fundacion Juan March Retrieved from https://books.google.es/books?id=RhruE CBuDwC\&q=Josef+Albers:+Minimal+mea ns, +maximum+effect\&dq=Josef+Albers: + Minimal+means, + maximum + effect $\& h l=t r$ $\& s a=X \& v e d=0 a h U K E w i 8 g O v H y b H i A h X x z O$ UKHS-ICMAQ6AEILDAA

Bayer, H., Gropius, I., \& Gropius, W. (1938). Bauhaus: 1919-1928. New York: The Museum of Modern Art. Retrieved from https://www.moma.org/documents/mo ma_catalogue_2735_300190238.pdf

Cross, N. (1982). Designerly ways of knowing. Design Studies, 3(4), 221-227. Retrieved from https://doi.org/10.1016/0142694X(82)90040-0

Dewey, J. (1938). Experience and education. Indianapolis: Kappa Delta Pi. Retrieved from https://books.google.es/books/about/Ex perience_and_education.html? $i d=x 4 p f 7 y$ ktCS4C\&redir_esc $=y$

Fablabs (n.d.). I'm new here. What's a Fablab?. Retrieved from https://www.fablabs.io/

Fablabs (n.d.). Map view [Digital image]. Retrieved from https://www.fablabs.io/labs/map

Gropius, W. (1919). Bauhaus manifesto and program. Retrieved from http://mariabuszek.com/mariabuszek/kc ai/ConstrBau/Readings/GropBau19.pdf

Gropius, W. (1965). The new architecture and the Bauhaus (Vol. 21). MIT press. 
Hochman, E. S., \& Ashton, D. (1997). Bauhaus: Crucible of modernism. New York: Fromm International. Retrieved from http://www.openbibart.fr/item/display/1 0068/944412

IAAC (n.d.). 3D Printing with soild and natural materials [Digital image]. Retrieved from http://pylos.iaac.net/main.html

ICD (n.d.). ICD/ITKE research pavilion 2013/14, design society [Digital image]. Retrieved from https://icd.unistuttgart.de/?p=21605

Jonassen, D. H. (1992). Evaluating constructivistic learning. In T.M. Duffy \& D. H. Jonassen (Eds.), Constructivism and the Technology of Instruction: A Conversation, (pp. 137-148). Retrieved from https://books.google.es/books?hl=tr\&lr=\& id $=4$ Qh GjtkoblUC \&oi=fnd\&pg=PA $136 \& d q$ =evaluating+constructivist+learning \&ots $=$ s4-

QmXWeko\&sig=3Kvb3gA $1 \mathrm{JZHHYYPAGPK}$ Cyh9ZWrE\&redir_esc $=y \# v=$ onepage $\& \mathrm{q}=$ evaluating constructivist learning \& $f=$ false

Kolarevic, B. (2003). Digital production. In Architecture in the digital age: design and manufacturing. New York: Taylor \& Francis. Retrieved from https://books.google.es/books?hl=tr\&lr=\& id $=\mathrm{L}-$

p4AgAAQBAJ\&oi=fnd\&pg $=P P 1 \& d q=$ digit al+production+kolarevic\&ots $=Q 4$ syEc $8 \mathrm{~V}$ $y \& s i g=L A 8$ s_U2XTwnOPWsjxcEMyj$\mathrm{mBQ} \&$ redir_esc $=\mathrm{y} \# \mathrm{v}=$ onepage $\& \mathrm{q}=$ digital production kolarevic \& $f=$ false

Makered (n.d.). Programa bauhaus. [image] Available at: http://makered.nl/wpcontent/uploads/2015/05/ProgramaBauhaus.png [Accessed 28 April 2019].
Peter, J. (1994). The oral history of modern architecture: interviews with the greatest architects of the twentieth century (Vol. 1). Harry $N$ Abrams Inc. Retrieved from https://books.google.es/books?hl=tr\&lr=\& $\mathrm{id}=\mathrm{JOHzlyF}$ R RfkC\&Oi=fnd\&pg=PA $1 \& d q=$ ne $w+t r e n d s+i n+a r c h i t e c t u r a l+e d u c a t i o n \& o t$ $\mathrm{s}=\mathrm{pBDfGiiu}$

V\&sig=0sA4RM9ad5d8L5wdd7dxImhhF7U \&redir_esc $=y \# v=$ onepage \& $q=$ new trends in architectural education \& $\mathrm{f}=\mathrm{false}$

Pye, D. (1978). Nature and aesthetics of design. London: Herbert Press Limited. Retrieved from

https://books.google.es/books?id=hTTaA AAAMAAJ\&dq=Nature\%20and\%20aesth etics\%20of\%20design.\&hl=tr\&source=gbs _ similarbooks

Salama, A. (1995). New trends in architectural education: Designing the design studio. North Carolina: Tailored Text and Unlimited Potential Publishing. Retrieved from

https://books.google.es/books?hl=tr\&lr=\& id $=J O H z l y F 8 R f k C \& O i=f n d \& p g=P A 1 \& d q=N$ ew+trends+in+architectural+education:+ Designing+the+design+studio\&ots $=p B D f l$ ohx5V \&sig=sN2jijiz $1 \mathrm{mP} 8+X \_9 g p X e R h Z R e T a$ E\&redir_esc $=y \# v=$ onepage \& $q=N e w \% 20 t r$ ends\%20in\%20architectural\%20education \%3A\%20Designing\%20the\%20design\%20st udio \& $\mathrm{f}=$ false

Siebenbrodt, M., \& Schöbe, L. (2009). Bauhaus (lst ed.). New York: Parkstone Press. Retrieved from https://books.google.es/books?id=QN5L1 HWBIVEC\&printsec $=$ frontcover\&hl=tr\&sou $r c e=g b s \_g e \_s u m m a r y \_r \# v=o n e p a g e \& q \&$ $\mathrm{f}=$ false 
www.ijcua.com

This page is intentionally left blank. 